\title{
Glycans as biochemical markers of human endometrial secretory differentiation
}

\author{
J. D. Aplin \\ Departments of Obstetrics \& Gynaecology, Biochemistry and Molecular Biology, \\ University of Manchester, St Mary's Hospital, Manchester M13 OJH, UK
}

\begin{abstract}
Summary. Uterine fluid contains a mixture of glycoprotein components the quantity and composition of which vary during the menstrual cycle. Their analysis may give clues to the involvement of maternally derived components in modulating the state of the peri-implantation blastocyst and aid in assessing the differentiation of the endometrium in preparation for implantation. Endometrial epithelium also exhibits an apical glycocalyx, the composition of which varies with the state of tissue differentiation. Evidence from animal systems suggests that glycans may be involved in molecular recognition between the embryo and maternal surface at implantation. Lectins and monoclonal antibodies to glycan epitopes have been used as sensitive and specific probes to examine the carbohydrates associated with endometrial epithelium as a function of the ovarian cycle. Numerous glycan structures are detected specifically in epithelial cells. Hitherto unsuspected biosynthetic heterogeneity is present in the glands. A secretory sialokeratan sulphate epitope is described, the occurrence of which coincides with the implantation phase of the cycle.
\end{abstract}

Kelwords: endometrium; implantation; carbohydrate; glycoprotein; lectin; monoclonal antibody; keratan sulphate; sialic acid; man

\section{Uterine glycans and reproductive function}

The uterine cavity is rich in glycans, both free in the aqueous compartment of glandular and uterine lumens, and as part of a rich glycocalyx at the apical surfaces of luminal (and glandular) epithelial cells. Broadly, these substances originate from two sources: the epithelium, which produces heavily glycosylated secretions and displays plasma membrane glycolipids and glycoproteins (Aplin, 1989); and the stroma, whence soluble glycoconjugates may be transcytosed to the uterine cavity, having originated in stromal cells or blood plasma (Beier et al., 1983). These components could, in principle, be involved in reproductive function in a number of capacities: protecting the upper genital tract from infection, interaction with spermatozoa before fertilization, rescue of the corpus luteum, interaction with the embryo in the preimplantation phase, and interaction during implantation, especially at the stage of attachment of the embryo to the epithelium. The demonstration of a hormonally controlled receptive phase or 'window' for embryo implantation in rodents (reviewed in Psychoyos, 1986) has given rise to speculation that the same may be true in humans. Despite detailed examination at the light and electron microscopic levels, no specific morphological feature of the receptive state has been identified. Molecular analysis is now required to achieve a better understanding of peri-implantation changes in endometrium, and to unravel the mechanism of embryo-maternal recognition.

Given widespread medical interest in the control of reproduction and assisted reproductive technologies, it is noteworthy that the physiological preparation of uterine tissue for the implanting embryo involves elaboration within endometrial epithelial cells of the biosynthetic machinery responsible for glycoprotein glycosylation, the Golgi apparatus, under the control of ovarian 
hormones (Dockery et al., 1988; Carson et al., 1990). Although the Golgi system can be detected in glandular epithelial cells in the proliferative phase (Aoki et al., 1989), ultrastructural studies (Dockery et al., 1988) have demonstrated that a significant increase occurs in apically located Golgi stacks between 3 and 6 days after the luteinizing hormone (LH) peak. This increase is correlated with the polarization of the cytoplasm and the appearance of more complex and extensive networks of apically oriented vesicular compartments, assumed to be the post-Golgi secretory apparatus. Further, it has long been known (see Dallenbach-Hellweg, 1981) that the volume of secretions in human endometrial glands increases in the luteal phase of the cycle, and that these contain carbohydrate, both in the form of glycogen (Wynn, 1977; Dockery et al., 1988) and glycoproteins (Themann \& Schünke, 1963).

Is there evidence that uterine glycans do play a role in reproductive function? In the light of evidence for the involvement of carbohydrate in a broad range of cell-cell interactions (Brandley \& Schnaar, 1986; Shur, 1989; Kojima \& Hakomori, 1989) including fertilization (Wassarman, 1987) and tumour metastasis ( $R a z \&$ Lotan, 1987), it is quite possible that glycoprotein and/or glycolipid oligosaccharide may be involved in the series of events surrounding implantation. However, molecular information on implantation-related events is scarce; direct manipulation of the uterine environment can give rise to artefacts (Chávez, 1990) and the alternative, a faithful in-vitro model of implantation that could be manipulated at the molecular level, is still not available (Denker, 1990; Mulholland \& Glasser, in press). Embryo transplantation studies in the early 1960s (Kirby, 1960, 1962) indicated that there might be substances present in the uterine milieu that encourage normal implantation and early development. More recently it has become clear that growth factors, nutrients and nutrient-carrier molecules, some of them glycosylated, are secreted into the uterine cavity in man and other species where it is assumed they function in the control of periimplantation embryonic metabolism (Roberts \& Bazer, 1988; Rutanen et al., 1988; Arceci et al., 1989; Bell \& Drife, 1989; Brigstock et al., 1989). However, it is not clear what, if any, role the carbohydrate plays in the function of these molecules.

Evidence has been obtained to demonstrate that changes occur in the thickness and composition of the apical glycocalyx of uterine epithelial cells in animals, most notably the rabbit (Anderson \& Hoffman, 1984; Anderson et al., 1986; Bükers et al., 1990), in the pre-implantation phase of pregnancy. The changes include a reduction of surface electronegativity, thinning of the glycocalyx and changes in lectin binding patterns. In equids, patches of surface epithelium that bind wheat-germ lectin have been observed in the peri-implantation luminal epithelium, extending after implantation to the rest of the epithelium including glands (Whyte \& Allen, 1985). Immunohistochemical analysis of mouse uterine epithelium using a panel of monoclonal antibodies to blood-group-associated carbohydrates has also revealed alterations in the cell and secretory glycan profile in early pregnancy (Kimber et al., 1988) under maternal endocrine control (Kimber \& Lindenberg, 1990). This has been followed by experiments using cultured monolayers of uterine epithelial cells in which the attachment of blastocysts was shown to be inhibited by the oligosaccharide lacto- $N$-fucopentaose I, which contains the blood group H type 1 structure (Table 2), at submillimolar concentrations (Lindenberg et al., 1988). The same oligosaccharide is expressed in restricted domains of the epithelium in vivo at the time of implantation (Kimber et al., 1988). Inhibition by the saccharide is, however, incomplete ( $\sim 60 \%$ of control levels at $0 \cdot 1 \mathrm{~mm}$ saccharide).

\section{Biochemical analysis of human endometrial glycoconjugates}

Biochemical analysis of the endometrial cell surface is still at a formative stage, especially in women (Aplin, 1989). Monoclonal antibodies raised to epithelial cells have been used to demonstrate cell surface alterations occurring after ovulation (Seif \& Aplin, 1990), and endometrial glycolipid profiles are also altered (Zhu et al., 1990). In the rabbit, changes in surface carbohydrate may arise from a combination of the appearance of new glycoproteins with alterations in the glycosylation 
patterns of conserved polypeptides (Anderson et al., 1986). Carson \& Tang (1989) have shown that cultured mouse uterine epithelial cells express lactosaminoglycans (sulphated as well as unsulphated) and heparan sulphates both of which bind to hydrophobic columns, suggesting the amphiphilic characteristics expected for cell surface constituents.

Endometrial secretions are easier to analyse either directly by flushing or withdrawal of uterine fluid (Beier et al., 1983), or by pulse-chase experiments on short-term tissue explants (Bell et al., 1985, 1986). Each method has disadvantages: the former may cause damage to the epithelium with the subsequent appearance of interstitial fluid in the specimen, while the latter overlooks exogenous components (e.g. plasma species transcytosed from the stromal compartment) which may be both glycosylated and quantitatively important. At least 20 different endogenous polypeptides have been detected using the pulse-chase method with $\left[{ }^{35} \mathrm{~S}\right]$ methionine (e.g. Bell, 1986), but it is not clear how many of these are glycosylated. One major glycoprotein product of mid- and late secretory phase endometrium and first trimester decidua, which originates in glandular epithelial cells, is the pregnancy-associated endometrial $\alpha_{2}$-globulin $\left(\alpha_{2}-\mathrm{PEG}\right)$, a dimeric lactoglobulin homologue of $M_{\mathrm{r}} 56000$ (Bell \& Drife, 1989), but no structural information is yet available on its glycans.

It is reasonable to assume that, as with other mucociliary epithelia, the endometrial surface is associated with one or more high-molecular-weight mucin glycoproteins (Allen, 1983; Laboisse, 1986) produced in gland cells. Since these molecules are often highly substituted with immunogenic oligosaccharides (including blood group substances), it is likely that some of the lectin and antibody binding discussed below is accounted for by the presence of mucin as a quantitatively major component of gland secretions. The elucidation of the structures of endometrial mucins and the hormonal control of their production and glycosylation is therefore of great interest. Van Kooij et al. (1982) analysed endometrial scrapings by $\mathrm{CsCl}$ density-gradient centrifugation and reported the presence of a sulphated sialomucin. We have detected a keratan-sulphate-containing glycoprotein, the properties of which could indicate that it is a mucin (Hoadley et al., 1990; see below); mucins in other tissues have frequently been shown to be sulphated (see, e.g. Ringler et al., 1987; Slomiany et al., 1988; Van Beurden-Lamers et al., 1989; Goso \& Hotta, 1989) and to carry lactosaminoglycans (Hanisch et al., 1989a). Given advances in mucin characterization (Bhavanandan \& Hegarty, 1987; Gendler et al., 1987; Bara et al., 1988; Linsley et al., 1988; Gum et al., 1989; Gupta \& Jentoft, 1989; Perini et al., 1989), further information should soon be available as to the mucin content of endometrium and its relationship to the more well-known cervical mucin.

\section{Histochemical analysis of endometrial epithelium}

Subject to accessibility and detection sensitivity, histochemical methods using the specific and, often, high-affinity binding of antibodies (Feizi \& Childs, 1987) and lectins (Sharon \& Lis, 1989) can be used to analyse endometrial glycans in situ. These methods have largely superceded older histochemical staining approaches (Themann \& Schünke, 1963; Jansen et al., 1985). The method does not give quantitative information or definitive evidence on the site of synthesis of the product detected, nor can it reveal characteristics of the individual macromolecules bearing the detected glycans. Indeed, a specific glycan can be expressed on more than one different macromolecule. Glycan histochemistry also suffers from a drawback that is pertinent in the analysis of a secretory epithelium, namely that it can never give definitive evidence as to the precise nature of the relationship between a binding site (sugar hapten) and a neighbouring cell surface. Many saccharide antigens have been found in association with both glycoproteins and glycolipids of the plasma membrane, but the same glycans can also be found in secretory substances (Carson \& Tang, 1989). It is therefore not possible to say, in the absence of biochemical information, whether a glycan detected in endometrial epithelium as part of the thick apical glycocalyx is integral to the plasma 
membrane, being secreted, or both, especially when there is evidence of intimate association between secretory substances and the cell surface (Campbell et al., 1988; Dutt \& Carson, 1990).

On the other hand, histological analysis gives information not otherwise available about the tissue compartment with which specific products are associated and about heterogeneity within tissue compartments. Thus, it is clear that in endometrial epithelium (see below) there is heterogeneity of glycan expression, giving rise to mosaicism within domains of the epithelium (Edwards, 1985). Indeed, antigenic heterogeneity unrelated to the cell cycle or clonal heterogeneity of the cell population appears to be a feature of many epithelia (Edwards, 1985). In endometrium this is further complicated by the presence of a variable proportion of ciliated cells (More \& Masterton, 1975), which are capable of producing secretory substances (Campbell et al., 1988).

\section{Lectin histochemistry of human endometrium}

Several authors have studied glycan expression in normal and pathological endometrium using panels of lectins (Lee \& Damjanov, 1985; Yen et al., 1986; Bychkov \& Toto, 1986, 1987; Söderstrom, 1987; Aoki et al., 1989; Kupryjanczyk, 1989; West \& Cope, 1989). Most of the lectins that have been used are shown in Table 1 with their corresponding binding specificities. Tissue preparation has varied from cryosectioning of unfixed tissue to routine paraffin-wax embedding of formaldehydeor picric-acid-fixed material. Fluorescence or peroxidase staining methods have been employed. Methodology is an important consideration because conflicting results have been obtained; for example, Kupryjanczyk (1989) used formalin-fixed, pronase-pretreated tissue, and detected abundant binding sites for PNA in proliferative and early secretory phase glands, and we have confirmed this finding using picric-acid-fixed, trypsin-pretreated tissue (Ward et al., 1990). Trypsin treatment gave a significant enhancement in the staining, which was abundant in basal and apical intracellular regions of the gland cells (for methods, see Jones et al., 1987; Kirkpatrick et al., 1988). In contrast, Bychkov \& Toto (1987), Söderstrom (1987), Aoki et al. (1989) and West \& Cope (1989), who did not pretreat their tissue sections with protease, reported that staining with PNA in the proliferative phase was confined to the apical surface of gland cells. Lee \& Damjanov (1985), who used acetone-fixed cryosections in conjunction with FITC-labelled PNA without protease pretreatment of the tissue, also failed to detect binding of PNA to intracellular components in the glands. Some glands were observed to stain at the apical cell surfaces, but others bound no detectable PNA. Thus while the glandular heterogeneity revealed by Lee \& Damjanov (1985) is genuine and interesting, their results, and those of the other groups, cannot be taken to indicate the absence of PNA-binding glycoproteins within the gland cells, but rather the presence of a glycan-masking mechanism. Masking is a protein-dependent phenomenon since protease pretreatment reveals new binding sites.

Since all cells produce glycosylated proteins, one would expect at least some lectins to bind in all regions of the tissue and this can readily be demonstrated with the lectins conA, PSA, LCA, L-PHA, e-PHA, and WGA (Fig. 1), all of which bind to sugar structures that occur predominantly in asparagine-linked glycans. This binding also shows rather little detectable menstrual cycle variation in any compartment of the endometrium (Lee \& Damjanov, 1985; Yen et al., 1986; Söderstrom, 1987; Bychkov \& Toto, 1986, 1987; Kupryjanczyk, 1989).

Several lectins have been observed to bind selectively to epithelial cells and their secretions. They include DBA (Fig. 2), LFA (Fig. 3), UEA-1, PNA, MPA, SBA and VVA. Many of the lectins (and antibodies; see next section) that show epithelial specificity bind to sugars that contribute to the terminal non-reducing parts of glycoprotein oligosaccharides. This might indicate that different processing enzymes are active in the epithelial Golgi apparatus, giving rise to different glycosylated structures in epithelial products; however, it cannot be excluded that the lectin binding data simply reflect greater amounts of Golgi-associated components in the epithelial cell compartment as compared with the stroma. 
Table 1. Lectins used to detect human endometrial glycans

\begin{tabular}{|c|c|c|c|}
\hline Source of lectin & Abbreviation & $\begin{array}{l}\text { Inhibitory } \\
\text { monosaccharide }\end{array}$ & Major binding specificity \\
\hline $\begin{array}{l}\text { Triticum vulgaris } \\
\text { (wheat germ) }\end{array}$ & WGA & GlcNAc & GlcNAc $\beta 1-4 G \mathrm{Gl} N A c$ \\
\hline $\begin{array}{l}\text { Arachis hypogaea } \\
\text { (peanut) }\end{array}$ & PNA & Gal & Galß1-3GalNAc \\
\hline $\begin{array}{l}\text { Canavalia ensiformis } \\
\text { (jack bean) }\end{array}$ & ConA & $\alpha$-Methyl mannoside & Man 1 1-3(Man 1 1-6)Man \\
\hline Pisum sativum (pea) & PSA & $\alpha$-Methyl mannoside & $\begin{array}{l}\alpha \text {-D-Mannose in non-bisected bi- and tri- } \\
\text { antennate, complex N-linked sequences }\end{array}$ \\
\hline $\begin{array}{l}\text { Lens culinaris (lentil) } \\
\text { Phaseolus vulgaris }\end{array}$ & LCA & a-Methyl mannoside & Similar to, but not identical with, PSA \\
\hline leucoagglutinin & L-PHA & None & $\begin{array}{c}\text { Gal } \beta-4 G 1 c N A c \beta 1 \\
\text { Mal } \beta 1-4 G l c N A c \beta 1 \\
/ 2\end{array}$ \\
\hline erythroagglutinin & E-PHA & None & $\begin{array}{r}\text { Gal } \beta 1-4 \text { GlcNAc } \beta 1-2 \text { Man } \alpha 1 \\
\text { GlcNAc } \beta 1-4 \mathrm{Man} \beta 1-4 \mathrm{R}^{*} \\
\text { GlcNAc } \beta 1-2 \mathrm{Man} \alpha \mathrm{l}\end{array}$ \\
\hline Limax flarus (slug) & LFA & NeuAc & Terminal $\alpha$-NeuAc \\
\hline Ulex europaeus & UEA-1 & Fuc & Terminal $\alpha$-fucose \\
\hline Tetragonolobus purpureus & LTA & Fuc & $\begin{array}{l}\text { Terminal } \alpha \text {-fucose, especially where } \\
\text { clustered }\end{array}$ \\
\hline Dolichos biflorus & DBA & GalNAc & $\begin{array}{l}\text { GalNAc } \alpha \text { l-3GalNAc; terminal } \\
\alpha \text {-GalNAc, especially on longer chains }\end{array}$ \\
\hline Maclura pomifera & MPA & Gal & $\begin{array}{l}\text { Certain } \alpha \text {-galactosyl and } \alpha-\mathrm{N} \text {-acetyl } \\
\text { galactosaminyl residues }\end{array}$ \\
\hline Glycine max (soyabean) & SBA & Gal, GalNAc & $\begin{array}{l}\text { Terminal } \alpha \text {-GalNAc, especially on } \mathrm{N} \text { - } \\
\text { linked glycans }\end{array}$ \\
\hline Vicia villosa & VVA & GalNAc & $\begin{array}{cc}\mathrm{H}_{2} \mathrm{~N} \text {-Ser-ProProGlyAlaAla } & \mathrm{ThCO}_{2} \mathrm{H} \\
1 \mid \alpha & 1 \mid \alpha \\
\text { GalNAc } & \text { GalNAc }\end{array}$ \\
\hline Bandeiraea simplicifolia & BSA-1 & Gal & Terminal $\alpha$-Gal and $\alpha$-GalNAc \\
\hline Ricinus communis & RCA-1 & Gal & $\begin{array}{l}\alpha \text {-Gal, } \beta \text {-Gal, especially on } N \text {-linked } \\
\text { glycans }\end{array}$ \\
\hline Erithrina crista-galli & ECA & Gal & Gal $\beta I-4 G l c N A c$ \\
\hline
\end{tabular}

${ }^{*} \mathrm{R}=\mathrm{GlcNAc} \beta 1-4 \mathrm{GlcNAc}$

In the light of the classical model of endometrial secretory transformation (with its associated large increase in Golgi and intracellular secretory apparatus; Dockery et al., 1988) occurring in the luteal phase, it is interesting that, with the help of peroxidase-labelled DBA, conA or RCA, Aoki et al. (1989) were able to detect the Golgi compartment in the apical cytoplasm of some proliferativephase gland cells. This is consistent with observations at the light microscope level of proliferative phase tissue showing intracellular binding sites for these three lectins (DBA is shown in Fig. 2) and L-PHA, WGA (Fig. 1), LTA, UEA-1 and PNA (Ward et al., 1990; Kupryjanczyk, 1989). It is also possible to detect in some glands the presence of intraluminal secretions in the proliferative phase (Fig. 1), consistent with the detection of secretory products in the medium of explant cultures of proliferative-phase tissue and epithelial cell cultures maintained in the absence of progesterone (Bell et al., 1986; Maudelonde \& Rochefort, 1987). Secretory transformation therefore involves up-regulation from a basal level of secretory activity.

However, lectin histochemistry demonstrates that secretory-phase glands differ from their proliferative-phase precursors in terms of the composition as well as the quantity of oligosaccharide 


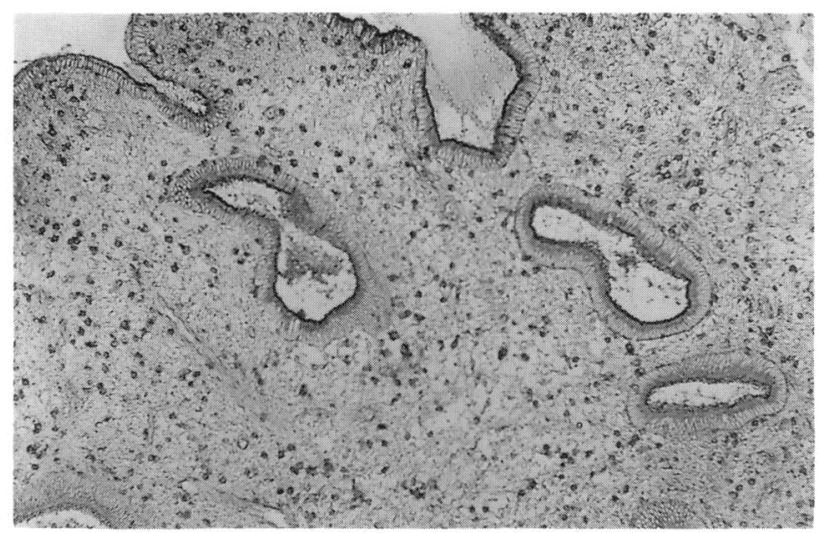

Fig. 1. Proliferative-phase human endometrium stained using peroxidase-conjugated wheat germ agglutinin (WGA), which binds to certain GlcNAc-containing oligosaccharides (Table 1). The stroma exhibits staining throughout, including a subpopulation of strongly positive cells. In the glands the most prominent staining is in the apical cytoplasms and surfaces of the cells, but strongly stained secretions are also visible in the gland lumens. Tissue was pretreated with trypsin. $\times 73$.

biosynthesis and secretion. We (Ward et al., 1990), West \& Cope (1989) and Aoki et al. (1989) have all noted a significant increase in the binding of DBA to gland cells and their secretions during the transition from proliferative to secretory phase (Fig. 2); in addition, Aoki et al. (1989) observed a similar pattern of alteration using SBA. There is a general tendency, revealed by several different lectins (DBA, PNA, UEA-1, LTA, L-PHA and LCA), for glycans present intracellularly in the proliferative and early secretory phases to become predominant in luminal secretory material in the mid-secretory phase with a concomitant decline in intracellular reserves in the mid- and late secretory phases (Kupryjanczyk, 1989). This is consistent with the classical pattern of secretory transformation, but it is worth noting that late secretory-phase gland cells still exhibit glycosylated products in the apical cytoplasm as revealed by the binding of conA and WGA (Ward et al., 1990). Kupryjanczyk (1989) noted that with one lectin, VVA, binding sites in gland cells did not appear before the 23rd day of the cycle.

We (M. E. Hoadley \& J. D. Aplin, unpublished) have noted an apparent increase in sialylation in the secretory phase as detected by binding of LFA (Fig. 3). This is consistent with the observation of new sialylated oligosaccharide determinants appearing in the secretory phase (see below) and with the increased binding of PNA in secretory-phase tissue pretreated with sialidase (West \& Cope, 1989). Thus sialic acid residues can act to mask lectin binding sites. These data do not, however, indicate an absence of sialylation in epithelial cells in the proliferative phase, since West $\&$ Cope (1989) also demonstrate increases in the binding of two lectins, MPA and BSA-1, when proliferative phase tissue is pretreated with sialidase. The observations are consistent with a probable increase in the electronegativity of the gland epithelial apical surface in secretory phase.

Interesting changes in the patterns of lectin staining of gland epithelial cells have been demonstrated in early pregnancy, confirming that, at least in the first trimester, the cells are not quiescent (Bell \& Drife, 1989). Lee \& Damjanov (1985) showed increases in the expression of VVA-, PNAand SBA-binding glycans and, at the same time, reductions in binding of LCA, E-PHA and L-PHA in the transition from proliferative phase to gestational glands.

Lee \& Damjanov (1985) also noted that a significant difference exists in proliferative phase tissue between gland and luminal epithelial cells in the expression of SBA-binding glycans, which were present both at the surface and intracellularly in the luminal epithelium, but absent from glands except for a weak binding in the basement membrane zone. This difference is of interest since the luminal epithelium is the site of implantation and because it appears against a 

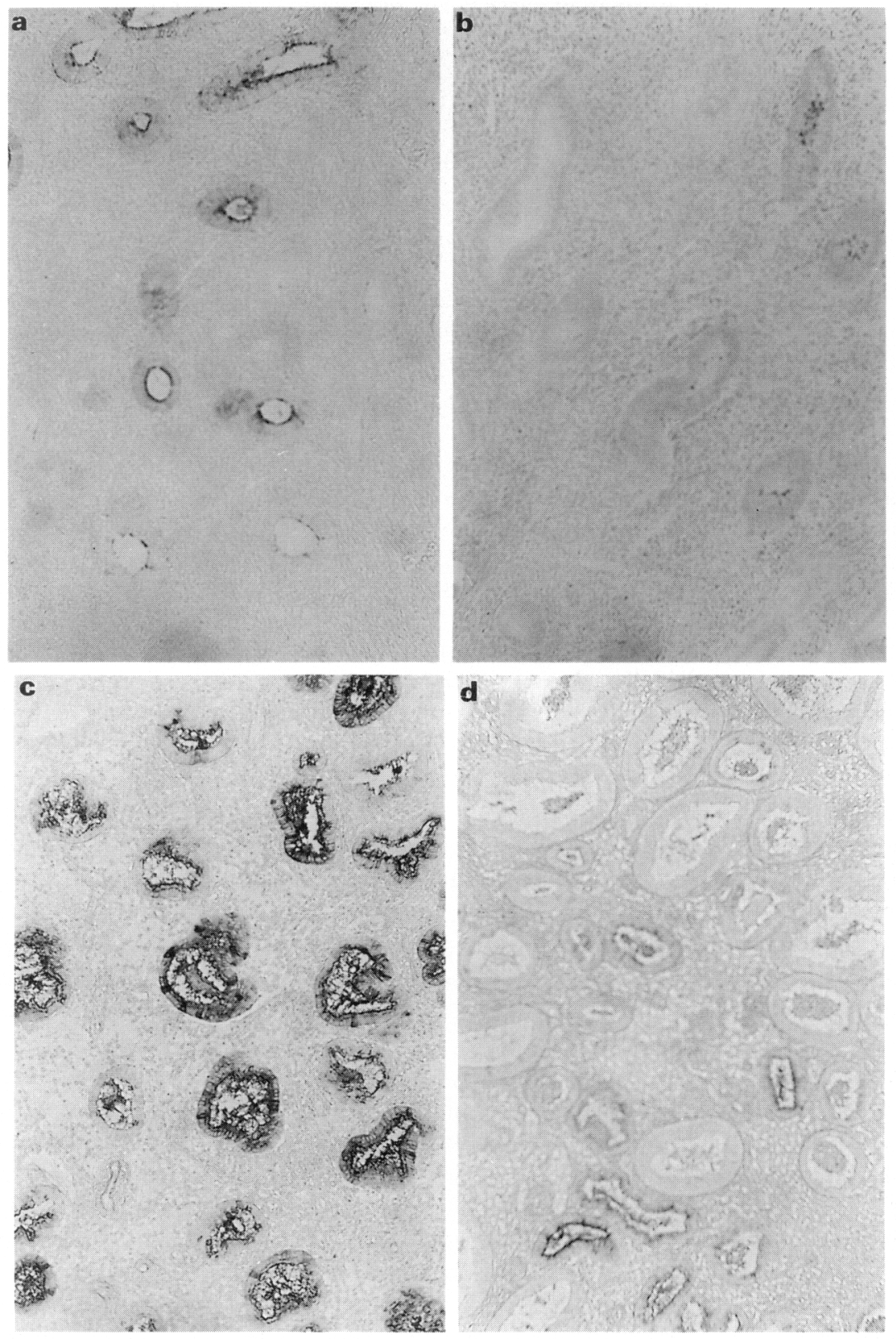

Fig. 2. Staining of human endometrium using peroxidase-conjugated Dolichos biflorus agglutinin (DBA), which binds terminal $\alpha$ GalNac residues. (a, b) Proliferative-phase tissue showing reactivity in a proportion of glands, confined to the apical part of the cells and occasional secretions. (c, d) Mid-secretory phase tissue. In a normal specimen (c) the extent of binding of the lectin to gland cells is significantly increased, with prominent cytoplasmic reactivity and secretory staining, while (d) shows a specimen from an IUD user with greatly reduced binding of the lectin. None of the tissues shows stromal staining. Tissue was pretreated with trypsin. $\times 73$. 

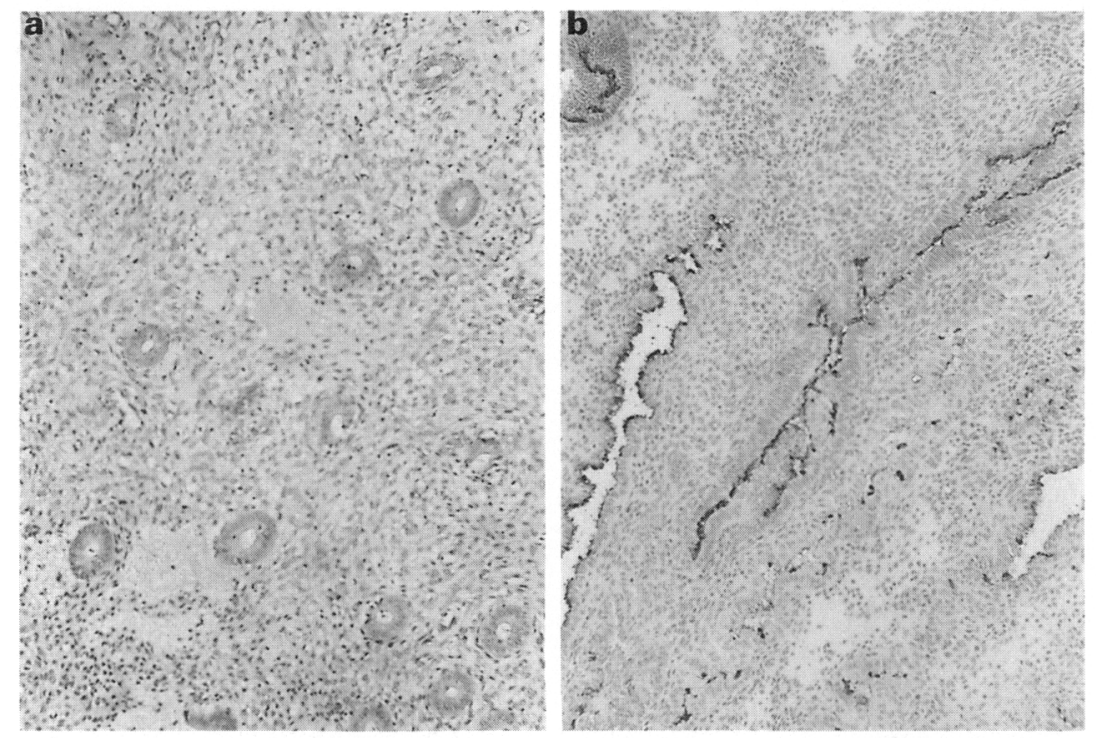

Fig. 3. Staining of human endometrium using the Limax flavus agglutinin (LFA), which recognizes sialic acid residues. No staining is visible in the proliferative phase (a), while in the secretory phase (b) apical reactivity is obvious in the glandular epithelium. Note that the tissue is counterstained with haematoxylin. There is no stromal reactivity. $\times 73$.

background of conservation of most glycans; amongst 22 lectins examined by Lee \& Damjanov (1985), only SBA revealed any qualitative difference between the two epithelial cell populations. Similarly, in a survey of 11 lectins, we (Ward et al., 1990) found slight differences in intensity of staining in a number of instances, but only one qualitative difference, the absence of binding sites for LCA at the apical surface of luminal cells throughout the cycle.

Heterogeneity within and between glands is a consistent feature of endometrium revealed by lectin histochemistry (see, e.g., Fig. 2) and also seen using antibodies to epithelial glycans (Figs $4 \& 5$ ). In all phases of the cycle it is common to find adjacent gland cells with very different levels of reactivity (Fig. 2). At the same time, neighbouring glands often show greatly differing levels of reactivity (Fig. 2). In the case of the fucose-binding lectin, UEA-1, only a small proportion of glands carry binding sites at any time of the cycle, even though these few glands can stain intensely. This appears to reflect an intrinsic heterogeneity in the glands, each of which may be derived from stem cells showing different properties, possibly representing different clonal origins (Gordon, 1989).

\section{Blood group and related antigens}

Szulman $(1960,1962)$ first reported the occurrence of blood group substances in epithelial secretions, at least in those $80 \%$ of the population who carry the $\mathrm{Se}$ gene and are known as secretors. The molecular genetic basis of blood group antigen occurrence has been documented (Yamamoto et al., 1990). Recently, Inoue et al. $(1987,1990)$ have investigated endometrium with the aid of specific monoclonal antibodies to the A, B, H and Lewis blood groups and related antigens (Table 2). Blood group antigen A was observed in apical gland epithelial cell cytoplasms, apical surfaces and secretions of most Group A and AB individuals. Blood group antigen B was weakly detected in a minority of $B$ individuals, and not in others. Antigen $\mathbf{H}$ appeared, again weakly, in a minority of individuals of Groups A, B or O. The Lewis a, sialyl Lewis a and Lewis b antigens were detected in 

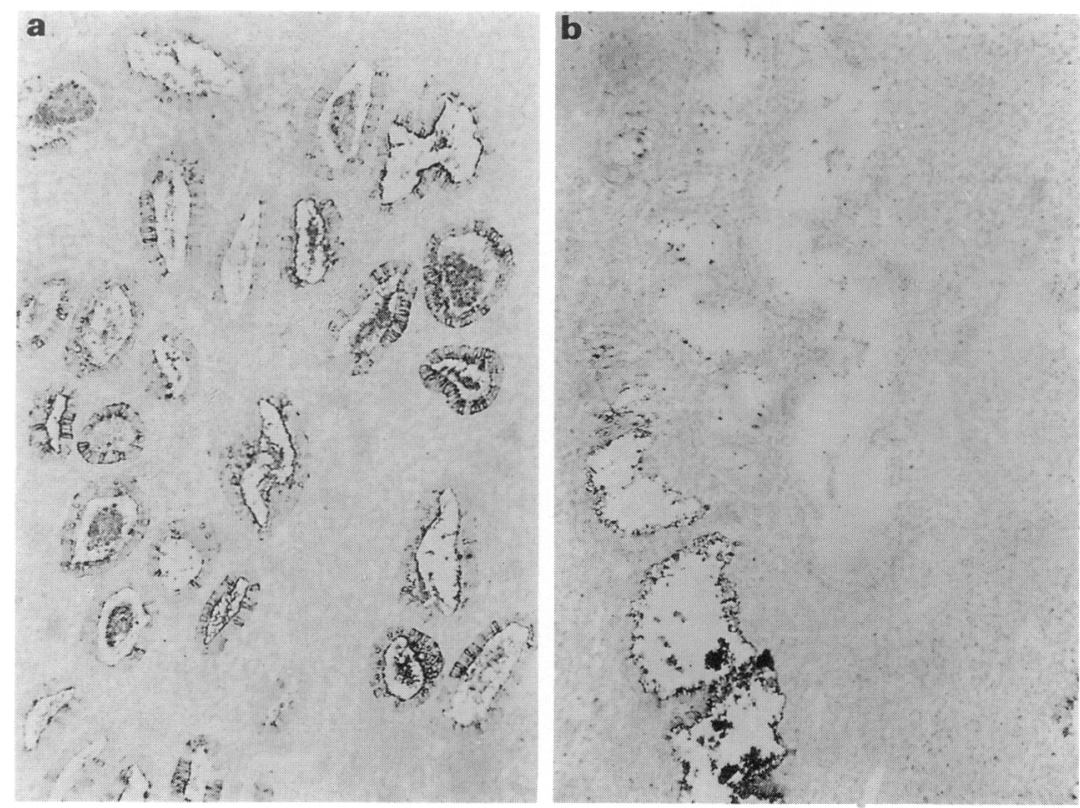

Fig. 4. Staining of mid-secretory phase human endometrium using monoclonal antibody 5D4, which binds to keratan sulphate, in an indirect immunoperoxidase method. Reactivity is confined to glandular (and surface) epithelium where it is associated with both cytoplasmic and luminal regions. Significant variation in staining is observed between different glands and even adjacent cells. A marked reduction in reactivity is seen after exposure to the IUD (b).

association with the apical surface of a minority of glandular epithelial cells. Low expression of Lewis b has been confirmed immunohistochemically and biochemically by Nozawa et al. (1989) and Iwamori et al. (1989) who also showed that this antigen is present as a glycosphingolipid, thus accounting for its association with the cell surface. More cells expressed the Lewis X (see also Garin-Chesa \& Rettig, 1989), sialyl Lewis X and Lewis $\mathrm{Y}$ antigens and these could be detected cytoplasmically. All of the antigens studied were present in both phases of the cycle, although a decrease in the abundance of the Lewis $X$ saccharide was observed in the secretory phase.

S. J. Kimber and S. Lindenberg (personal communication) have investigated the expression in human endometrium of the blood group H type I structure that they had earlier found to be expressed on luminal epithelial cells in mouse (Kimber et al., 1988). They have confirmed that the structure is present, but a significant proportion is masked by sialylation. After treatment of tissue with sialidase, gland cells in the proliferative phase and secretions in the secretory phase are each intensely stained, with an increase in the overall level of expression in midsecretory phase.

A sialoglycan epitope has been reported, the behaviour of which shows a strong menstrual cycle dependency. Monoclonal antibody B72.3 recognizes a determinant present on a high- $M_{\mathrm{r}}$ glycoprotein called TAG-72 in breast carcinoma (Johnson et al., 1986). The epitope is also present in other types of carcinoma. TAG-72 has several properties that identify it as a mucin, including an estimated $M_{\mathrm{r}}$ of 220000400000 (although unsheared preparations are reported as having still greater $M_{\mathrm{r}}$ ) and the presence of oligosaccharide chains bearing the blood group antigens Lewis a, Lewis b, $\mathrm{H}$ type 2 and sialylated Lewis $\mathrm{X}$, as well as the trisaccharide antigen NeuAca2-6(Galp13)GalNAc (Hanisch et al., 1989b). The B72.3 epitope is not identical to any of these antigens, but binding of the antibody is significantly diminished after treatment of the glycoprotein with sialidase (Johnson et al., 1986). The epitope is expressed in human endometrial epithelium in the secretory 

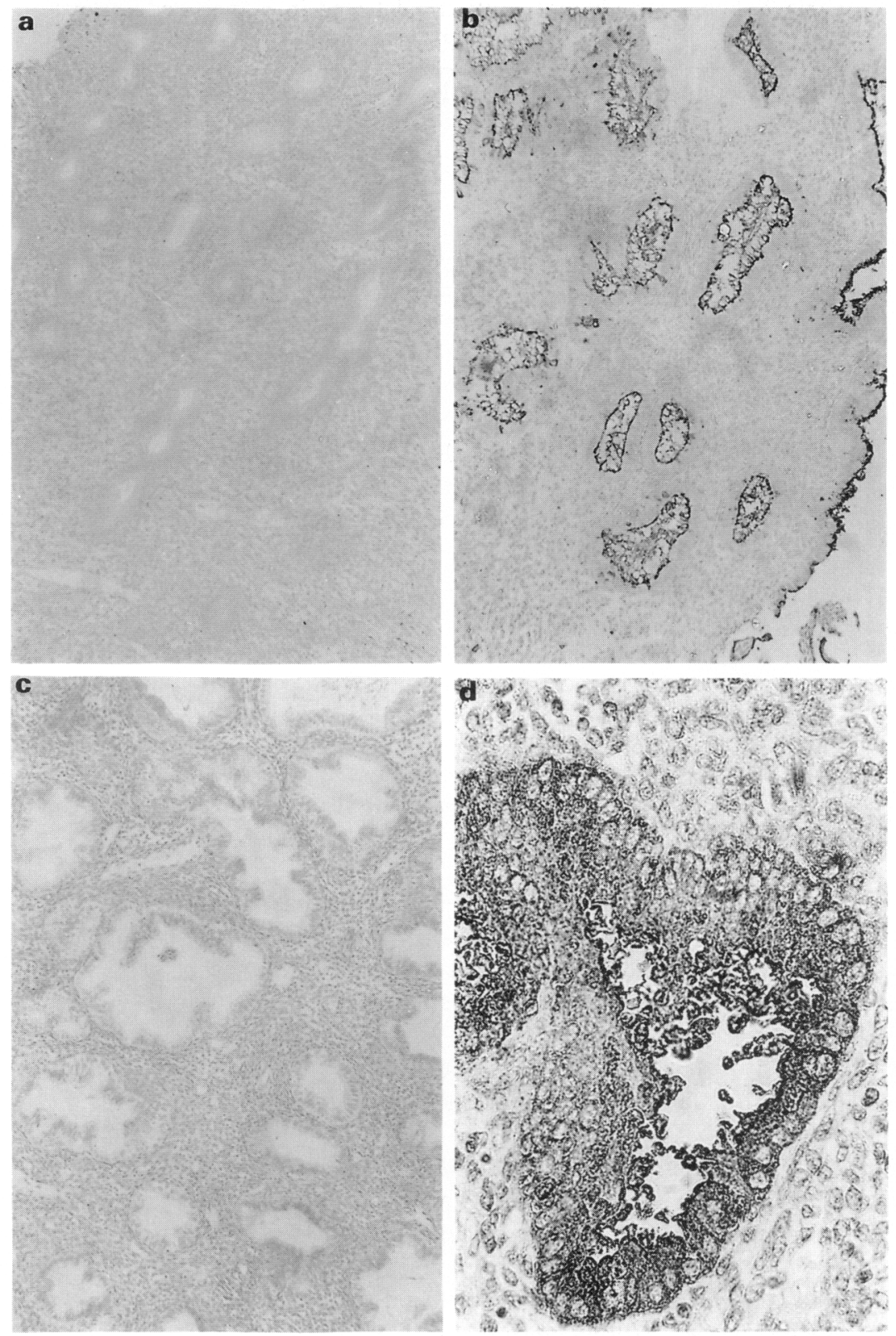

Fig. 5. Staining of human endometrium with monoclonal antibody D9B1 using an indirect immunoperoxidase method. (a) Proliferative phase with no antigen present (the tissue is lightly counterstained); (b) mid-secretory tissue showing prominent immunoreactivity associated with the glandular and surface epithelium; (c) higher magnification of a mid-secretory phase gland demonstrating that the immunostaining is present throughout glandular cell cytoplasms, at their apical surfaces and in secretions; (d) a mid-secretory endometrium after exposure to an IUD showing a drastic reduction in expression of the D9B1 epitope. None of the specimens shows stromal reactivity. (a), (b) and (d); $\times 73$ (c) $\times 364$. 
Table 2. Some carbohydrate antigens detected in human endometrial epithelium and secretions*

\begin{tabular}{r}
\hline Gal $\beta 1-[4 G l c N A$ \\
GalNAc $1-3 \mathrm{G}$ \\
$\alpha 2$ \\
$\alpha \mid 1$ \\
Fuc
\end{tabular}

GalNAca1-3Galß1-4GlcNAc

2

$\alpha \cdot 1$

Fuc

Gal 1 1-3Gal $\beta 1-3 \mathrm{GlcNAc}$
$\alpha \mid \begin{aligned} & 2 \\ & 1\end{aligned}$
Fuc

Gala1-3Galß1-4GIcNAc

$\left.\alpha\right|^{2}$

Fuc

Galß1-3-GlcNAc

$\alpha \mid \begin{aligned} & 4 \\ & 1\end{aligned}$

Fuc

Galß1-3GlcNAc

$\left.\left.\alpha\right|_{1} ^{2} \quad \alpha\right|^{4} 1$

Galp1-3GlcNAc

$\left.\alpha\right|_{1} ^{2}$

Fuc

Gal $\beta 1-4 G l c N A c$

$\left.\alpha\right|_{1} ^{2}$

Fuc

Gal $\beta 1-4 G l c N A c$

$\alpha \mid \begin{aligned} & 3 \\ & 1\end{aligned}$

Fuc

Galp1-4GlcNAc

$\alpha \mid \begin{array}{ll}2 & \alpha \\ 1 & 3 \\ 1\end{array}$

Fuc Fuc

GlcNAc $\beta 1-[3 \mathrm{Gal} \beta 1-4 \mathrm{GlcNAc} \beta 1]-3 \mathrm{Gal}$

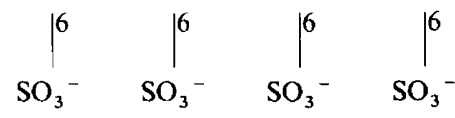

Polylactosamine

A type $1 \dagger$

A type $2 \dagger$

B type 1

B type 2

Lewis a

Lewis $b$

H type $1 \ddagger$

H type $2+$

Lewis $\mathrm{X}$

Lewis $Y$

Keratan sulphate (5D4

epitope); less sulphated forms also present

*Sialylated chain variants are frequently expressed; see text.

$\dagger$ A structures are recognized by the lectin DBA.

$\ddagger$ H, structures are recognized by the lectins UEA- 1 and LTA.

phase, and is absent in the proliferative phase (Soisson et al., 1989). However, the precise cycle dependence of its expression will require the use of tissue dated with respect to the LH peak (Dockery et al., 1988; Smith et al., 1989). It is not yet clear how many of the other glycan structures 
(i.e. those not recognized by antibody B72.3) are also associated with the glycoprotein in endometrium since all the characterization has been done with TAG-72 extracted from breast carcinoma.

\section{Keratan sulphates and related glycans}

Recently we have identified sulphated lactosaminoglycan (keratan sulphate) as a secretory product of endometrium (Fig. 4) using antibodies (such as monoclonal antibody 5D4; Mehmet et al., 1986; Funderburgh et al., 1987) specific for highly sulphated oligosaccharides of which the chain variant of highest binding affinity is shown in Table 2. This is consistent with the report of sulphated mucin detected in human endometrial secretions (van Kooij et al., 1982). The presence of the parent polylactosamine chain is also consistent with observations in rodents; polylactosamine biosynthesis is stimulated by oestrogen in mice and expression occurs both at the epithelial cell surface and in secretions (Dutt et al., 1988; Dutt \& Carson, 1990). As discussed above, blood group antigens of the $\mathrm{A}, \mathrm{B}, \mathrm{H}$ and Lewis systems, for which lactosamine forms the core structure, occur in endometrial epithelium of mice and humans. Other blood-group-related structures based on the lactosamine core and including various terminal chain extensions have been detected in mice by Babiarz \& Hathaway (1988), Kimber et al. (1988) and Kimber \& Lindenberg (1990) and shown to be influenced by the endocrine environment. Strips of rat uterine tissue produce secretory keratan sulphate as well as other sulphated glycans including heparan sulphate, and these increase in response to stimulation with oestrogen (Carson et al., 1988). Cell culture experiments have demonstrated that the keratan sulphate is produced in epithelial cells which secrete the protoglycan to the apical compartment from polarized, confluent monolayers. The $M_{\mathrm{r}}$ from size-exclusion chromatography is 130000 , and several keratan chains appear to be present. Although relatively little is yet known about the biosynthesis of sulphated glycoconjugates, it is clear that sulphation occurs in the Golgi apparatus. It is interesting in this context to note that the enzymatic sulphation of glycoconjugates in rabbit uterus is under hormonal control: oestrogen stimulates sulphotransferase activity as measured in microsomal fractions from the tissue, and progesterone suppresses the effect (Isemura et al., 1981; Munakata et al., 1985).

The highly sulphated keratan chain type recognized by monoclonal antibody 5D4 (Mehmet $e t$ al., 1986; Funderburgh et al., 1987) is associated in human endometrium primarily with a proteaseresistant glycoprotein that exhibits an apparent $M_{\mathrm{r}}$ of 140000 on SDS-PAGE (Hoadley et al., 1990). The keratan chains appear to be of the O-linked class (Hoadley et al., 1990) as in the rat endometrium (Carson et al., 1988). The structure is expressed in about a quarter of proliferative-phase glands, but the proportion of positive glands increases progressively to the mid-secretory phase, at which time most glands are expressing (Fig. 4). When present it occurs in cytoplasmic as well as cell surface locations and in secretions. There is therefore progressive up-regulation from a basal level of expression. This basal production is achieved not by a low uniform level of biosynthesis throughout the tissue, but rather by maintenance of higher production in a few glands.

We have detected another keratan chain type in endometrial secretions (Aplin et al., 1988; Hoadley et al., 1990), this one associated with a high- $M_{\mathrm{r}}(250000-350000)$ glycoprotein with some of the characteristics of a mucin. In this case the polylactosamine chains appear to carry sulphate at a lower degree of substitution than in the $M_{\mathrm{r}} 140000$ glycoprotein; this was deduced from the sensitivity of the high- $M_{\mathrm{r}}$ glycoprotein-associated keratan chains to degradation with the enzymes endo- $\beta$-galactosidase and keratanase, both of which hydrolyse glycosidic linkages adjacent to unsulphated galactose. This second class of keratan chains carries a terminal sialic acid residue that is associated with the epitope recognized by monoclonal antibody D9B1. The expression of this epitope in non-pregnant endometrium is, like many other glycans, confined to the epithelium, but in this case it is highly hormonally regulated (Fig. 5). The D9B1 epitope is not detectable in 
proliferative-phase tissue, but appears in gland cells starting 2-3 days after the LH peak. A rapid increase in production follows, and it is secreted into gland lumens where it reaches a maximum level 6-7 days after the LH peak, thus coinciding with the expected time of implantation (Seif et al., 1989c; Smith et al., 1989). These data provide evidence that molecular changes occur in the tissue at this crucial time, and raise important questions as to the function of glycoprotein glycans in implantation-related events.

\section{Glycosylation changes in endometrial pathology}

Antibodies to blood group substances have been used in carcinomata of various secretory tissues to demonstrate changes in expression, often giving rise to structures 'inappropriate' in the context of the individual's phenotype (see Yamamoto et al., 1990). Thus, for example, in endometrium the Lewis $b$ and Lewis $\mathrm{Y}$ antigens are expressed much more strongly in adenocarcinoma than in normal glands (Inoue et al., 1990). The Lewis b antigen is carried on a glycosphingolipid, the concentration of which may be elevated by up to 2 orders of magnitude compared with the normal tissue (Iwamori et al., 1989). The same antigens also occur in foetal endometrium, as a result of which they have been designated as oncofoetal markers in the tissue (Inoue et al., 1990). At the same time, changes occur in the sensitivity of the cells to regulation by ovarian steroids. Thus it is clear that glycosylation pathways are sensitive to the differentiation of the endometrial epithelial cell in pathological as well as in normal states.

It is therefore of interest, in the context of the possible involvement of glycans in reproductive function, to compare their expression in infertile and normal endometrium. Users of the intrauterine contraceptive device are reversibly infertile. We have found that expression of the sialylated and non-sialylated keratan sulphate chains recognized by monoclonal antibodies D9B1 and 5D4, respectively, are significantly diminished in the epithelium of IUD users (Figs 4 \& 5; Seif et al., 1989 a; J. D. Aplin \& M. W. Seif, unpublished). These changes were not related to the degree of inflammatory change observed in the tissue. Furthermore, they occurred against a background of broad conservation of glycan chain composition as monitored by a panel of lectins (N. H. Ward, J. D. Aplin \& R. W. Stoddart, unpublished) with which only rather minor alterations could be discerned in IUD-exposed tissue. One noteworthy change, however, was the decrease in binding of DBA observed in IUD-exposed tissue (Fig. 2). All these three reagents that show IUD effects recognize glycan structures that show an increase in expression in the secretory phase, suggesting that the IUD may affect specific late post-translational events in the cells as they respond to hormonal stimulation.

We have also used antibodies 5D4 (J. D. Aplin \& M. W. Seif, unpublished) and D9B1 (Seif et al., 1989b) to study secretory differentiation in women exhibiting luteal-phase defect as diagnosed by conventional histology. This is a complex and heterogeneous condition, but in two-thirds of the study group diminished reactivity was observed with the two antibodies. This correlated well with infertility. Finally, antibody D9B1 has recently been used to examine luteal-phase endometrium from women with unexplained infertility (Graham et al., 1990). Again, the infertile group displayed a significantly diminished level of epitope, and in this study it also emerged that women whose luteal-phase progesterone concentrations were within the normal range continued to show reduced expression. This therefore constitutes novel evidence of infertility resulting from a primary endometrial dysfunction.

\section{Conclusions}

The endometrial epithelium expresses a rich diversity of glycan chains, with an overall increase in glycosylation from the proliferative to the secretory phase as expected given the corresponding 
progesterone-stimulated increase in Golgi apparatus. As the secretory phase evolves, glycans are mobilized from the apical cytoplasm of gland cells across the apical plasma membrane and into the lumens. A considerable heterogeneity of expression is revealed between cells in the same gland, and between different glands. Luminal and glandular epithelia express broadly the same patterns of glycan structures, though some differences are observed that support the concept of specialized functions at the two sites.

Generally, glycan structural patterns are conserved through the cycle in the epithelium, but specific compositional changes are detectable using certain lectins or, more readily, monoclonal antibodies of the desired specificity. The differentiation markers so far most clearly delineated are terminal $\alpha-N$-acetyl galactosamine groups recognized by the lectin DBA, sialic acid residues recognized by the lectin LFA, and keratan sulphates recognized by monoclonal antibodies D9B1 and 5D4. These all increase in the secretory phase, the most dramatic changes being in the sialoglycans recognized by LFA and D9B1, which peak in the peri-implantation period.

It will now be important to determine whether these observations reflect changes in the level of specific secretory glycoconjugates under progesterone domination, or alterations in the levels of Golgi-localized enzymes (sialyl transferase: Paulson et al., 1989; sulphotransferase: Munakata et al., 1985; $\alpha$-N-acetyl galactosaminyl transferase), which may be adjusted to alter glycosylation patterns on nascent glycoproteins.

Finally, evidence suggests that endometrial glycosylation is sensitive to pathological change in the tissue including infertility. This finding should encourage further work designed to test the hypothesis that endometrial glycoconjugates may be involved in interactions with the blastocyst during implantation.

\section{References}

Allen, A. (1983) Mucus-a protective secretion of complexity. Trends Biochem. Sci. 8, 169-173.

Anderson, T.L. \& Hoffman, L.H. (1984) Alterations in epithelial glycocalyx of rabbit uteri during early pseudopregnancy and pregnancy, and following ovariectomy. Am. J. Anat. 171, 321-334.

Anderson, T.L., Olson, G.E. \& Hoffman, L.H. (1986) Stage-specific alterations in the apical membrane glycoproteins of endometrial epithelial cells related to implantation in rabbits. Biol. Reprod. 34, 701-720.

Aoki, D., Kawakami, H., Nozawa, S., Udagawa, Y. \& Hirano, H. (1989) Differences in lectin binding patterns of normal human endometrium between proliferative and secretory phases. Histochemistry 92, $177-184$.

Aplin, J.D. (1989) Cellular biochemistry of the endometrium. In Biology of the Uterus, pp. 89-129. Eds R. M. Wynn \& W. P. Jollie. Plenum Press, New York.

Aplin, J.D., Hoadley, M.E. \& Seif, M.W. (1988) Hormone-dependent expression of keratan sulphate in endometrium. Biochem. Soc. Trans. 17, 136-137.

Arceci, R.J., Shanahan, F., Stanley, E.R. \& Pollard, J.W. (1989) Temporal expression and location of colony stimulating factor 1 (CSF-1) and its receptor in the female reproductive tract are consistent with CSF-1regulated placental development. Proc. natn. Acad. Sci. USA 86, 8818-8822.

Babiarz, B.S. \& Hathaway, H.J. (1988) Hormonal control of the expression of antibody-defined lactosaminoglycans in the mouse uterus. Biol. Reprod. 39, $699-706$.
Bara, J., Gautier, R., Le Pendu, J. \& Oriol, R. (1988) Immunochemical characterization of mucins. Polypeptide (MI) and polysaccharide (A and Le $\mathrm{e}^{\mathrm{b}}$ ) antigens. Biochem. J. 254, 185-193.

Beier, H.M., Beier-Hellwig, K. \& Delbos, R. (1983) Hormones and proteins involved in uterine preparation for implantation. In Fertilisation of the Human Egg in vitro, pp. 307-327. Eds H. M. Beier \& H. R. Lindner. Springer-Verlag, Berlin.

Bell, S.C. \& Drife, J.O. (1989) Secretory proteins of the endometrium--potential markers for endometrial dysfunction. Clin. Obstet. Gynaecol. 3, 271-29l.

Bell, S.C., Hales, M.W., Patel, S.R., Kirwan, P.H. \& Drife, J.O. (1985) Protein synthesis and secretion by the human endometrium and decidua during early pregnancy. Br. J. Obstet. Gynaecol. 92, 793-803.

Bell, S.C., Patel, S.R., Kirwan, P.H. \& Drife, J.O. (1986) Protein synthesis and secretion by the human endometrium during the menstrual cycle and the effect of progesterone in vitro. J. Reprod. Fert. 77, 221-231.

Bhavanandan, V.P. \& Hegarty, J.D. (1987) Identification of the mucin core protein by cell-free translation of messenger RNA from bovine submaxillary glands. $J$. biol. Chem. 262, 5913-5917.

Brandley, B.K. \& Schnaar, R.L. (1986) Cell-surface carbohydrates in cell recognition and response. J. Leukocyte Biol. 40, 97-111.

Brigstock, D.R., Heap, R.B. \& Brown, K.D. (1989) Polypeptide growth factors in uterine tissues and secretions. J. Reprod. Fert. 85, 747-758.

Bükers, A., Friedrich, J., Nalbach, B.P. \& Denker, H.W. (1990) Changes in lectin binding patterns in rabbit 
endometrium during pesudopregnancy, early pregnancy and implantation. Trophoblast Res. 4, 285306.

Bychkov, V. \& Toto, P.D. (1986) Lectin binding to normal human endometrium. Gynecol. Obstet. Invest. 22, $29-33$

Bychkov, V. \& Toto, P.D. (1987) Histochemical study of lectin binding to gestational endometrium. Int. $J$. Ginecol. Pathol. 6, 66-72.

Campbell, S., Seif, M.W., Aplin, J.D., Richmond, S.J., Haynes, P. \& Allen, T.D. (1988) Expression of a secretory product by micro-villous and ciliated cells of the human endometrial epithelium in vivo and in vitro. Hum. Reprod. 3, 927-934.

Carson, D.D. \& Tang, J.-P. (1989) Estrogen induces $\mathrm{N}$-linked glycoprotein expression by immature mouse uterine epithelial cells. Biochemistry, $N Y \mathbf{2 8}, 8116-$ 8123.

Carson, D.D., Tang, J.P., Julian, J. \& Glasser, S.R. (1988) Vectorial secretion of proteoglycans by polarized rat uterine epithelial cells. J. Cell Biol. 107, 2425-2435.

Carson, D.D., Farrer, J.D., Laidlaw, J. \& Wright, D.A. (1990) Selective activation of the $\mathrm{N}$-glycosylation apparatus in uteri by estrogen. J. biol. Chem. 265, 2947-2955.

Chávez, D. (1990) Possible involvement of D-galactose in the implantation process. Trophoblast Res. 4, 259 272.

Dallenbach-Hellweg, G. (1981) Histopathology of the Endometrium. Springer Verlag, Berlin.

Denker, H.-W. (1990) Trophoblast-endometrial interactions at embryo implantation: a cell biological paradox. Trophoblast Res. 4, 3-29.

Dockery, P., Li, T.C., Rogers, A.W., Cooke, 1.D. \& Lenton, E.A. (1988) The ultrastructure of the glandular epithelium in the timed endometrial biopsy. Hum. Reprod. 3, 826-834.

Dutt, A. \& Carson, D.D. (1990) Lactosaminoglycan assembly, cell surface expression, and release by mouse uterine epithelial cells. J. biol. Chem. 265, $430-438$.

Dutt, A., Tang, J.-P. \& Carson, D.D. (1988) Estrogen preferentially stimulates lactosaminoglycan-containing oligosaccharide synthesis in mouse uteri. J. biol. Chem. 263, 2270-2279.

Edwards, P.A.W. (1985) Heterogenous expression of cell-surface antigens in normal epithelia and their tumours, revealed by monoclonal antibodies. $\mathrm{Br} . J$. Cancer 51, 149-160

Feizi, T. \& Childs, R.A. (1987) Carbohydrates as antigenic determinants of glycoproteins. Biochem. J. 245, I 11 .

Funderburgh, J.L., Caterson, B. \& Conrad, G.W. (1987) Distribution of proteoglycans antigenically related to corneal keratan sulphate proteoglycans. $J$. biol. Chem. 262, I1634-11640.

Garin-Chesa, P. \& Rettig, W.J. (1989) Immunohistochemical analysis of LNT, NeuAc2-3LNT and Le $^{x}$ carbohydrate antigens in human tumours and normal tissues. Am. J. Pathol. 134, 1315-1327.

Gendler, S.J., Burchell, J.M., Duhig, T., Lamport, D., White, R., Parker, M. \& Taylor-Papadimitriou, J. (1987) Cloning of partial cDNA encoding differentiation and tumor-associated mucin glycoproteins expressed by human mammary epithelium. Proc. natn. Acad. Sci. USA 84, 6060-6064.
Gordon, J.I. (1989) Intestinal epithelial differentiation: new insights from chimeric and transgenic mice. $J$. Cell Biol. 108, 1187-1194.

Goso, Y. \& Hotta, K. (1989) Types of oligosaccharide sulphation, depending on mucus glycoprotein source, corpus or antral, in rat stomach. Biochem. $J$. 264, 805-812.

Graham, R.A., Aplin, J.D., Seif, M.W., Li, T.C., Cooke, I.D. \& Rogers, A.W. (1990) An endometrial factor in unexplained infertility. Br. med. J. 330, 1428-1431.

Gum, J.R., Byrd, J.C., Hicks, J.W., Toribara, N.W., Lamport, D.T.A. \& Kim, Y.S. (1989) Molecular cloning of human intestinal mucin cDNAs. Sequence analysis and evidence for genetic polymorphism. $J$. biol. Chem. 264, 6480-6487.

Gupta, R. \& Jentoft, N. (1989) Subunit structure of porcine submaxillary mucin. Biochemistry, NY 28, $6114 \cdots 6121$.

Hanisch, F.-G., Uhlenbruck, G., Egge, H. \& PeterKatalinic, J. (1989a) A B72.3 second generation monoclonal antibody (CC49) defines the mucincarried carbohydrate epitope Galß1-3(NeuAca2-6) GalNAc. Biol. Chem. Hoppe-Sevler 370, 21-26.

Hanisch, F.-G., Uhlenbruck, G., Peter-Katalinic, J., Egge, H., Dabrowski, J. \& Dabrowski, U. (1989b) Structures of neutral O-linked polylactosaminoglycans on human skim milk mucins. A novel type of linearly extended poly- $\mathrm{N}$-acetyllactosamine backbones with Gal $\beta(1-4)$ GlcNAc $\beta(1-6)$ repeating units. $J$. biol. Chem. 264, 872883.

Hoadley, M.E., Seif, M.W. \& Aplin, J.D. (1990) Menstrual cycle-dependent expression of keratan sulphate in human endometrium. Biochem. J. 266, 757-763.

Inoue, M., Nakayama, M. \& Tanizawa, O. (1990) Altered expression of Lewis blood group and related antigens in fetal, normal adult and malignant tissues of the uterine endometrium. Virchow's Arch. A Pathol. Anat. 416, 221-228.

Inoue, M., Sasagawa, T., Saito, J., Shimizu, H., Ueda, G., Tanizawa, O. \& Nakayama, M. (1987) Expression of blood group antigens A, B, H, Lewis-a and Lewis-b in fetal, normal and malignant tissues of the uterine endometrium. Cancer 60, 2985-2993.

Isemura, M., Munakata, H. \& Yosizawa, Z. (1981) Hormonal effects on the sulfation of sulfated glycoprotein in particulate fractions of the endometrium of rabbit uterus. J. Biochem. (Tokyo) 89, 1815-1819.

Iwamori, M., Sakayori, M., Nozawa, S., Yamamoto, T., Yago, M., Noguchi, M. \& Nagai, Y. (1989) Monoclonal antibody-defined antigen of human uterine endometrial carcinomas is $\mathrm{Le}^{\mathrm{b}}$. J. Biochem. 105, $718-722$.

Jansen, R.P.S., Turner, M., Johannison, E., Landgren, B.-M. \& Diczfalusy, E. (1985) Cyclic changes in human endometrial surface glycoproteins: a quantitative histochemical study. Fert. Steril. 44, 85-91.

Johnson, V.G., Schlom, J., Paterson, A.J., Bennett, J., Magnani, J.L. \& Colcher, D. (1986) Analysis of a human tumor-associated glycoprotein (TAG-72) identified by monoclonal antibody B72.3. Cancer Res. 46, $850-857$.

Jones, C.J.P., Mosley, S.M., Jeffrey, I.J.M. \& Stoddart, R.W. (1987) Elimination of the non-specific binding of avidin to tissue sections. Histochem. J. 19, 264 268 . 
Kimber, S.J. \& Lindenberg, S. (1990) Hormonal control of a carbohydrate epitope involved in implantation in mice. J. Reprod. Fert. 89, 1321.

Kimber, S.J., Lindenberg, S. \& Lundblad, A. (1988) Distribution of some Galß1-3(4)GIcNAc related carbohydrate antigens on the mouse uterine epithelium in relation to the per-implantational period. J. Reprod. Immunol. 12, 297-313.

Kirby, D.R.S. (1960) Development of mouse eggs beneath the kidney capsule. Nature, Lond. 187, 707. 708.

Kirby, D.R.S. (1962) The influence of the uterine environment on the development of mouse eggs. J. Embryol. exp. Morph. 10, 496-506.

Kirkpatrick, C.J., Jones, C.J.P. \& Stoddart, R.W. (1988) Lectin histochemistry of the mast cell. A light microscopical study. Histochem. J. 20, $139 \cdots 146$.

Kojima, N. \& Hakomori, S.-I. (1989) Specific interaction between gangliotriasylceramide $\left(\mathrm{Gg}_{3}\right)$ and sialosyllactosylceramide $\left(\mathrm{G}_{\mathrm{M} 3}\right)$ as a basis for specific cellular recognition between lymphoma and melanoma cells. J. biol. Chem. 264, 20159-20162.

Kupryjanczyk, J. (1989) Cycle- and function-related changes in lectin binding to human endometrium: a histochemical study with pronase treatment. Arch. Gynecol. Obstet. 246, 211-221.

Laboisse, C.L. (1986) Structure of gastrointestinal mucins: searching for the Rosetta stone. Biochimie $\mathbf{6 8}$, $611 \cdot 617$.

Lee, M.-C. \& Damjanov, I. (1985) Pregnancy-related changes in the human endometrium revealed by lectin histochemistry. Histochemistry 82, 275-280.

Lindenberg, S., Sundberg, K., Kimber, S.J. \& Lundblad, A. (1988) The milk oligosaccharide, lacto-N-fucopentaose I, inhibits attachment of mouse blastocysts on endometrial monolayers. J. Reprod. Fert. 83, 149 158.

Linsley, P.S., Kallestad, J.C. \& Horn, D. (1988) Biosynthesis of high molecular weight breast carcinoma associated mucin glycoproteins. J. biol. Chem. 263, 83908397.

Maudelonde, T. \& Rochefort, H. (1987) A 51K progestinregulated protein secreted by human endometrial cells in primary culture. J. clin. Endocr. Metab. 64, 1294-1301.

Mehmet, H., Scudder, P., Tang, P.W., Hounsell, E.F., Caterson, B. \& Feizi, T. (1986) The antigenic determinants recognised by three monoclonal antibodies to keratan sulphate involve sulphated hepta- or larger oligosaccharides of the poly( $\mathrm{N}$-acetyllactosamine) series. Eur. J. Biochem. 157, 385-391.

More, I.A.R. \& Masterton, R.G. (1975) The fine structure of the human endometrial ciliated cell. J. Reprod. Fert. 45, 343-348.

Mulholland, J. \& Glasser, S.R. (in press) Uterine preparation for blastocyst attachment. In Cellular Signals Controlling Uterine Function, Ed. G. Lavia. Plenum, New York.

Munakata, H., Isemura, M. \& Yosizawa, Z. (1985) Enzymatic sulphation of exogenous high molecular weight glycopeptides by microsomal fraction of the rabbit uterine endometrium. J. biol. Chem. 260, 6851-6856.

Nozawa, S., Sakayori, M., Ohta, K., lizuka, R., Mochizuki, H., Soma, K., Fujimoto, J.-I., Hata, J.-I., Iwamori, M. \& Nagai, Y. (1989) A monoclonal antibody (MSN-1) against a newly established uterine endometrial cancer cell line (SNG-II) and its application to immunohistochemistry and flow cytometry. Am. J. Obstet. Gynecol. 161, 1079-. 1086.

Paulson, J.C., Weinstein, J. \& Schauer, A. (1989) Tissuespecific expression of sialyltransferases. J. biol. Chem. 264, 10931-10934.

Perini, J.-M., Marianne, T., Lafitte, J.-J., Lamblin, G., Roussel, P. \& Mazzuca, M. (1989) Use of an antiserum against deglycosylated human mucins for cellular localization of their peptide precursors: antigenic similarities between bronchial and intestinal mucins. J. Histochem. Cytochem. 37, 869-875.

Psychoyos, A. (1986) Uterine receptivity for nidation. Ann. N.Y. Acad. Sci. 476, 36-39.

Raz, A. \& Lotan, R. (1987) Endogenous galactosidebinding lectins: a new class of functional tumour cell surface molecules related to metastasis. Cancer Metast. Rev. 6, 433-452.

Ringler, N.J., Selvakumar, R., Woodward, H.D., Simet, I.M., Bhavanandan, V.P. \& Davidson, E.A. (1987) Structure of canine tracheobronchial mucin glycoprotein. Biochemistry, $N Y$ 26, 5322-5328.

Roberts, R.M. \& Bazer, F.W. (1988) The functions of uterine secretions. J. Reprod. Fert. 82, 875-892.

Rutanen, E.-M., Pekonen, F. \& Makinen, T. (1988) Soluble $34 \mathrm{~K}$ binding protein inhibits the binding of insulin-like growth factor I to its cell receptors in human secretory phase endometrium: evidence for autocrine/paracine regulation of growth factor action. J. clin. Endocrinol. Metab. 66, 173-180.

Seif, M.W. \& Aplin, J.D. (1990) Cell surface components of human endometrial epithelium: monoclonal antibody studies. Trophoblast Res. 4, 339-356.

Seif, M.W., Aplin, J.D., Awad, H. \& Wells, D. (1989a) The effect of the intrauterine contraceptive device on endometrial secretory function. An immunohistochemical study. Contraception 40, 81-89.

Seif, M.W., Aplin, J.D. \& Buckley, C.H. (1989b) Luteal phase defect: the possibility of an immunohistochemical analysis. Fert. Steril. 51, 273-279.

Seif, M.W., Aplin, J.D., Foden, L.J. \& Tindall, V.R. (1989c) A novel approach for monitoring the endometrial cycle and detecting ovulation. Am. J. Obstet. Gynecol. 160, 357-362.

Sharon, N. \& Lis, H. (1989) Lectins. Chapman \& Hall, London.

Shur, B.D. (1989) Expression and function of cell surface galactosyltransferase. Biochim. Biophys. Acta 988, 389409.

Slomiany, B.L., Piotrowski, J., Nishikawa, H. \& Slomiany, A. (1988) Enzymatic sulfation of salivary mucins: structural features of 35S-labeled oligosaccharides. Biochem. Biophys. Res. Commun. 157, 61-67.

Smith, R.A., Seif, M.W., Rogers, A.W., Li, T.C., Dockery, P., Cooke, I.D. \& Aplin, J.D. (1989) The endometrial cycle: the expression of a secretory component correlated with the luteinising hormone peak. Hum. Reprod. 4, 236-242.

Söderström, K.-O. (1987) Lectin binding to formalinfixed paraffin sections of human endometrium. Int. $J$. Gynecol. Pathol. 6, 55-65.

Soisson, A.P., Berchuck, A., Lessey, B.A., Soper, J.T., Clarke-Pearson, D.L., McCarty, K.S. \& Bast, R.C. 
(1989) Immunohistochemical expression of TAG-72 in normal and malignant endometrium: correlation of antigen expression with estrogen receptor and progesterone receptor levels. Am. J. Obstet. Gynecol. $161,1258-1263$.

Szulman, A.E. (1960) The histological distribution of blood group substances A and B in man. J. exp. Med. $111,785799$.

Szulman, A.E. (1962) The histological distribution of blood group substances in man as disclosed by immunofluorescence. II. The $\mathrm{H}$ antigen and its relation to A and B antigens. J. exp. Med. 115, 977-995.

Themann, H. \& Schünke, W. (1963) The fine structure of the glandular epithelium of the human endometrium. Electron microscopic morphology. In The Normal Human Endometrium, pp. 99-100. Ed. H. G. SchmidtMatthiesen. McGraw-Hill, New York.

Van Beurden-Lamers, W.M.O., Spee-Brand, R., Dekker, J. \& Strous, G.J. (1989) Sulphation causes heterogeneity of gastric mucins. Biochim. Biophys. Acta 990, 232 239 .

Van Kooij, R.J., Roelofs, H.J.M., Kathman, G.A.M. \& Kramer, M.F. (1982) Synthesis of a mucous glycoprotein in the human uterus. Eur. J. Obstet. Gynecol. Reprod. Biol. 14, 191-197.

Wassarman, P. (1987) The biology and chemistry of fertilization. Science, N.Y. 235, 553560.
Ward, N.H., Aplin, J.D., Benbow, E.W. \& Stoddart, R.W. (1990) Glycosylation in endometrial epithelium in the normal cycle and with intrauterine contraceptive devices. J. Path. 160, 166A.

West, K.P. \& Cope, J.L. (1989) The binding of peroxidase-labelled lectins to human endometrium in normal cyclical endometrium and endometrial adenocarcinoma. J. clin. Pathol. 42, 140-147.

Whyte, A. \& Allen, W.R. (1985) Equine endometrium at preimplantation stages of pregnancy has specific glycosylated regions. Placenta 6, 537-542.

Wynn, R.M. (1977) Histology and ultrastructure of the human endometrium. In Biology of the Uterus, pp. 341-376. Ed. R. M. Wynn. Plenum, New York.

Yamamoto, F., Clausen, H., White, T., Marken, J. \& Hakomori, S. (1990) Molecular genetic basis of the histo-blood group ABO system. Nature, Lond. 345, 229-233

Yen, Y., Lee, M.-C., Salzmann, M. \& Damjanov, I. (1986) Lectin binding sites on human endocervix: a comparison with secretory and proliferative endometrium. Anat. Rec. 215, 262-266.

Zhu, Z., Deng, H., Fenderson, B.A., Nudelman, E.D. \& Tsui, Z. (1990) Glycosphingolipids of human myometrium and endometrium and their changes during the menstrual cycle, pregnancy and ageing. J. Reprod. Fert. 88, 71-79. 